\title{
Reflexões sobre as políticas de gestão de recursos humanos
}

\author{
Fellipe Coelho-Lima ${ }^{1}$ e Camila Costa Torres ${ }^{2}$ \\ Departamento de Psicologia da \\ Universidade Federal do Rio Grande do Norte (Natal, RN)
}

\begin{abstract}
O objetivo desse trabalho foi levantar o atual discurso empresarial sobre as políticas de gestão de recursos humanos e compreender suas consequências para a classe trabalhadora. A revisão bibliográfica elegeu algumas obras que retratavam o discurso empresarial e as críticas a este. Identificou-se que as políticas de gestão de recursos humanos são voltadas para a estratégia e a competitividade empresarial, alinhando os membros da empresa com a política da empresa, utilizando-se das competências dos trabalhadores para concorrência da empresa. O discurso empresarial defende a autonomia e o desenvolvimento pessoal do trabalhador e a flexibilização das relações de trabalho. A crítica a esse discurso aponta que a autonomia defendida é limitada à resolução de problemas de produção. Os projetos de desenvolvimento pessoal dentro das organizações interferem nas subjetividades dos trabalhadores, havendo um severo rebatimento dessas propostas sobre a saúde do trabalhador e da sua alienação sobre a consciência de classe. O estudo indica dois caminhos para discussão: o da evidenciação das políticas de gestão de recursos humanos como um possível lugar de lutas e conquistas para os trabalhadores e a necessidade de os psicólogos assumirem ações politizadas.
\end{abstract}

Palavras-chave: Políticas de gestão de recursos humanos, Discurso empresarial, Alienação do trabalhador.

Reflections on human resources policies

This paper aimed to research the current business discourse about the human resources policies and understand the consequences of those to the working class. A literature review was held and some works, that portrayed the business discourse and the criticisms directed to it, were selected. Being found that the human resources policies are geared towards the strategy and organizational competitiveness, aligning the member of the organization with the company strategy and using the workers' competences as competitiveness to the corporation. The business discourse defends the autonomy of the workers, the personal development of the employee and the flexibility of the working relations. The critic about this discourse indicates that the autonomy defended is limited to the solution of problems on production. The personal development projects inside the organization interfere in the subjectivities of the workers, happening a severe bounce of these proposals about the workers' health and their alienation about the class consciousness. The study indicates two paths for discussion: the disclosure of the human resources policies as a possible place of struggle and achievements for the workers, and the urge of the psychologists to take political actions.

Keywords: People management policies, Business discourse, Worker alienation.

$\mathrm{N}$ atual contexto de desenvolvimento histórico da sociedade capitalista, notam-se mudanças cruciais nas configurações econômicas, sociais e políticas dos países, marcadamente a partir da década de 1970. Essas transformações conferem um tom diferenciado às posturas adotadas pelas empresas tanto quanto à concepção de produção como ao modo de gerir as pessoas.

Nesse cenário, muitas questões são colocadas à área de recursos humanos, de modo que o presente estudo propõe: a) descrever o panorama geral e os elementos determinantes de

1 Psicólogo. Mestrando do Programa de Pós-Graduação da Universidade Federal do Rio Grande do Norte. Membro do Grupo de Pesquisas Marxismo \& Educação.

2 Professora do Departamento de Psicologia da Universidade Federal do Rio Grande do Norte. 
algumas mudanças na área de recursos humanos; b) apresentar o discurso vigente quanto às suas prescrições; c) levantar algumas considerações a respeito da função ideológica e dos efeitos dessas prescrições para os trabalhadores; e d) realizar algumas considerações sobre o potencial de ação das políticas de gestão de recursos humanos (RH) e do psicólogo diante desse quadro.

Para alcançar esses objetivos, realizou-se uma revisão bibliográfica que, se não exaustiva, pretendeu elencar os elementos básicos que constituem tanto o discurso empresarial a respeito da área de recursos humanos como os principais pontos de crítica levantados por autores pertencentes, principalmente, ao campo da Sociologia e da Psicologia do Trabalho. Por meio do diálogo entre essas duas literaturas, pretende-se transportar esse debate para o campo de atuação do psicólogo, já que ele é convidado a contribuir para as novas propostas na área de recursos humanos.

A discussão dessas temáticas é relevante para incentivar o desenvolvimento de profissionais de Psicologia e áreas afins com uma consciência crítica em relação a sua atuação, para questionar posturas arraigadas e propor reposicionamentos diante dos cenários que se configuram.

Dois conceitos guiarão boa parte das análises, sendo o primeiro o de discurso empresarial e o outro, o de classe trabalhadora. Quanto ao primeiro termo, esse tipo de discurso inclui-se na categoria de discurso ideológico e, por tanto, foge do campo puramente idealista e abstrato, circunscrevendo-se como um conjunto de prescrições orientadas à prática. Os discursos ideológicos, não se confundem com as ações reais dos sujeitos coletivos ou individuais: ele é um corolário de valores, crenças e recomendações, mas não é a tradução exata das ações e comportamentos impressos na realidade (Mészáros, 2004). Assim, o discurso empresarial é o desdobramento de uma ideologia global, ligado a esta pelos valores que carrega, aplicando a um contexto específico - o de gerenciamento dos processos empresariais - as prescrições que constam nessa ideologia macro e hegemônica. Isso significa afirmar que esse discurso é o suporte normativo dentro das empresas, que transferem para o plano simbólico e prático os preceitos capitalistas (Boltanski \& Chiapello, 2009).

O segundo conceito de partida é o de classe trabalhadora. Historicamente, essa é uma das (se não a) categorias fundamentais para a discussão empreendida por Marx e a literatura marxista (Bottomore, Harris, Kiernan \& Miliband, 2001). Ela é constituída pelos sujeitos que, desprovidos de meios materiais de produção, possuem apenas a sua força de trabalho como mercadoria de troca dentro do mercado capitalista. Por sua vez, o polo oposto desse binômio, o capitalista, é aquele que detém os meios materiais para a produção de mercadorias e necessita da força de trabalho para que a criação e a valorização do capital se concretizem (Marx, 1867/2010). Assim, a base para a constituição da sociedade, sob a égide do capital, é a relação (conflituosa e antagônica) entre o trabalho e o capital ${ }^{3}$.

Diante das novas configurações sociais, esse conceito carece de redimensionamento (Bottomore et al., 2001) e, para isso, serão considerados neste artigo alguns apontamentos feitos por Antunes $(2007,2010)$. Para o autor, esse conceito deve incluir todos os sujeitos que vivem da venda de sua força de trabalho, nas suas mais diversas formas. Incluem-se os trabalhadores assalariados do setor de serviços, subempregados, desempregados, terceirizados, trabalhadores rurais e, dentre tantos outros trabalhadores que sofrem a exploração do capital no processo de obtenção de extração de mais-valia, seja essa participação direta ou indireta. Contudo, continuam excluídos dessa classe os altos gerentes, os especuladores da economia, bem como os proprietários rurais e os pequenos burgueses.

3 Contudo, essa dialética fundamental da sociedade não resume as diversas classes que a compõem. Outras classes, como a média, composta por pequenos burgueses e profissionais liberais, também estão incluídas, aliando-se, ao sabor dos interesses, a um ou outro polo da relação (Marx, 1867/2010). 


\section{Mudanças no contexto mundial}

No século XX o mundo assistiu a uma grave crise do capital, com seu maior pico na década de 1970. Ela foi o reflexo do esgotamento do padrão de acumulação e de organização do trabalho do taylorismo/fordismo, ao mesmo tempo em que se configurou como mais uma das crises cíclicas do capitalismo (Havey, 1989).

No plano econômico, notou-se a dificuldade desse modelo em manter os níveis de rendimento de outras décadas, diante do surgimento de novos mercados mais exigentes e dos conflitos com os sindicatos, que clamavam por maior distribuição da renda da produção (Ferreira, 1997). No plano social, o embate entre o trabalho e o capital se mostrou cada vez mais acalorado. A classe trabalhadora, com maior acesso à educação (em virtude do Estado de Bem-Estar Social) e com maior articulação sindical, limitava a exploração promovida pelas empresas, combatendo o sistema de trabalho repetitivo e desprovido de sentido, característico desse modelo (Antunes, 2007; Ferreira, 1997).

Diante de tantas pressões, era imperativa para a manutenção da ordem capitalista a reconsideração de alguns de seus pressupostos, sem, com isso, autorizar a desconstrução desse sistema produtivo. Dessa forma, inaugurou-se na década de 1980 a implantação da acumulação flexível do capital (Antunes, 2007, 2010). Alguns dos elementos basilares que garantiram a concretização desse processo foram: a revolução tecnológica, a mundialização do mercado e da produção, o incremento da competitividade organizacional e o desemprego estrutural.

A Revolução Tecnológica foi uma das principais viabilizadoras do processo de flexibilização das ações de trabalho na sociedade capitalista, por meio do incremento tecnológico, fundamentalmente na área de microtecnologia, desencadeando o desenvolvimento das tecnologias informacionais conjugadas às inovações gerenciais (Nakano, 1994). Em grande parte, o desenvolvimento tecnológico foi motivado pela necessidade de imprimir maior controle sobre a produção das mercadorias e da redução da quantidade de trabalhadores por atividade (Antunes, 2007). Essa foi uma estratégia que contribuiu para a desarticulação dessa classe, ao passo que muitos postos de trabalhos foram fechados e os grandes coletivos de trabalhadores foram reduzidos. Em decorrência da possibilidade (quase) ilimitada de interação entre as pessoas, viabilizou-se ainda, em grande parte, o processo de mundialização do mercado, quantitativa e qualitativamente diferente do que em outras épocas.

Também é característico desse período o adensamento da competição entre as empresas. Após uma década de intenso crescimento da produção, verificou-se o esgotamento do sistema com a redução do capital produtivo (Antunes, 2007). Viu-se que o mercado consumidor encontrava-se em processo de retração, impelindo as empresas a buscar alternativas de crescimento, seja pelas transações financeiras, seja por mudanças dos processos de produção (Antunes, 2007).

Nesse ínterim, uma das respostas mais difundidas foi o modelo toyotista (Antunes, 2007; Gounet, 1999). Enfocando a flexibilização da produção de mercadorias e das relações de trabalho, foi o modelo que mais se difundiu pelos diversos países (Bernardo, 2009). Algumas de suas características básicas são: o foco na demanda de mercado, a organização do trabalho baseada em equipes e projetos, a produção just in time, a utilização de estoques mínimos, a criação de estruturas horizontalizadas, a terceirização de parte da força de trabalho e os Círculos de Controle de Qualidade (Antunes, 2007). Todavia, esse modelo sofreu adaptações pelo mundo, sendo mesclado com filosofias e práticas oriundas do taylorismo/fordismo (Bernardo, 2009).

Por outro lado, ocorreram alterações também no quadro de relação entre o capital e o trabalho com o aumento do desemprego. A partir da crise de 1970 e das respostas dadas pelo capital, verificou-se uma queda estrutural no número de empregos formais (Antunes, 2007, 
2010). Em parte, essa situação relaciona-se ao incremento do uso da tecnologia, que tende a reduzir a quantidade de cargos que exigem baixa qualificação, mantendo e priorizando aqueles que requerem maior qualificação e capacidade de interação com a tecnologia (Mészáros, 2006; Pochmann, 2006a).

Essa situação impele a parte menos favorecida da classe trabalhadora a cada vez mais ingressar no mercado informal e nos trabalhos precarizados (temporários, terceirizados etc.), havendo uma cisão no interior da própria classe trabalhadora, enfraquecendo o seu potencial combativo (Mészáros, 2006). Esse elemento foi fundamental para o processo de flexibilização do capital na medida em que o exército de reserva produzido pelos trabalhadores desempregados fortalece o poder das empresas no processo de negociação junto aos trabalhadores. Essa configuração conduziu progressivamente a um processo de despolitização da classe trabalhadora, que, em décadas passadas, se apresentou como empecilho para a expansão capitalista (Antunes, 2007, 2010).

Já nas empresas, nota-se um ambiente que demanda maior dinamismo produtivo, exigindo a reorganização do modo de se conceberem os diversos níveis e processos da empresa. Mohrman e Lawler III (1995) listam quatro principais imposições às empresas nesse ambiente: (1) possuir uma estratégia sólida para atuar de maneira resoluta no ambiente; (2) ser competitiva perante o mercado; (3) integrar facilmente os processos de mudança organizacional; e (4) envolver plenamente os sujeitos com a empresa.

Essa situação favorece o uso do discurso pelas/nas empresas de planejamento estratégico, que visa estabelecer planos de ações das empresas direcionadas ao ambiente nos quais elas participam (Albuquerque, 2002). É objetivo de tal discurso promover a integração dos diversos setores da empresa para que, unidos, alcancem a expansão no mercado concorrencial. O planejamento estratégico, tradicionalmente, pode ser encarado como um processo de formalização (decomposição, articulação e racionalização) dos guias mais gerais que regem a empresa para o futuro (Mintzberg, 2004). Está em pauta a evidenciação sistemática e minuciosa de quais são as metas e objetivos da empresa e, por conseguinte, de cada unidade e setor. Teoricamente, esse procedimento é que garantiria uma melhor colocação e projeção da empresa no mercado ao longo dos anos.

Outra característica que desponta na literatura sobre gerenciamento é a questão do pessoal que compõe a empresa como elementos ao mesmo tempo estratégicos e competitivos (Bohlander, Snell \& Sherman, 2003; Fischer, 2002). Instala-se, então, uma visão de gestão de pessoas com enfoque estratégico e competitivo. Contudo, esse não é, ao longo dos tempos, o único modelo adotado para lidar com o fator humano nas empresas: de acordo com o contexto social e histórico no qual a empresa se insere, esses modelos sofreram interferências e alterações. Assim como aponta Alves (1995), as diversas fases da gestão de recursos humanos no Brasil foram fortemente influenciadas pelas diversas configurações do embate político e social com os trabalhadores.

\section{O discurso da moderna gestão de recursos humanos}

Para melhor compreender alguma das prescrições do discurso empresarial voltado para a gestão de $\mathrm{RH}$, construir-se-ão, nas próximas linhas, os seus elementos basilares. Para tanto, as afirmativas listadas foram extraídas de autores como Albuquerque (2002), Aquino (1980), Bohlander et al. (2003), Carvalho e Nascimento (1993), Chiavenato (1998, 2008), Dutra (2006), Fleury (2002), Marras (2000), Mohrman e Lawler III (1995), Pimenta (1999), Robbins (2005), Ulrich (2003), dentre outros. Vários desses textos constituem-se como 
consagrados manuais sobre gestão de recursos humanos e outros abordam esse tema juntamente com outras discussões (principalmente da área de Administração).

Identificou-se que para alguns autores que corroboram o discurso empresarial, como Chiavenato (2008) e Ulrich (2003), a área de recursos humanos, na atualidade, define-se como um órgão de consultoria interna, sendo característica de sua equipe ser: a) polivalente, b) enxuta, c) dinâmica e proativa na busca e resolução de problemas dentro da empresa.

Essa mesma literatura concorda que esse novo papel apenas seja possível com a descentralização da função de controle de problemas de pessoal, passando a ser compartilhado com os gerentes das linhas de produção (Lacombe \& Tonelli, 2001). Há uma dispersão das antigas funções do RH de auxílio na resolução de problemas individuais dos funcionários (eventualidades do dia a dia) para as gerências de linha, ao mesmo tempo em que compartilha essas decisões inerentes aos seus setores, como a seleção, treinamento e o desenvolvimento de pessoal. O RH apresenta-se como colaborador, conselheiro e facilitador na criação, implantação e execução de práticas e ações voltadas para os trabalhadores, em parceria com as diversas gerências.

Ainda é presente nesse discurso que as políticas e práticas de RH são decorrentes dos objetivos organizacionais (Aquino, 1980; Bohlander et al., 2003; Carvalho \& Nascimento, 1993; Chiavenato, 1998, 2008; Dutra, 2006). Assim sendo, é fundamental para o RH inserir-se no nível estratégico da empresa, derivando suas ações da filosofia mais ampla, a fim de colaborar para o alcance dos objetivos e metas estabelecidas estrategicamente. $\mathrm{O}$ mesmo discurso expõe ainda que a área de RH deve formalizar o seu planejamento estratégico, a fim de se alinhar direta e racionalmente ao plano adotado pela empresa como um todo. Assim, distante de ser considerada apenas uma área geradora de despesas (como em outros momentos foi tomada), o RH é considerado uma área de geração de lucros, por meio do manejo de pessoas (Alves, 1995).

Como Fischer (2002) assinala, a área de RH torna-se estratégica na medida em que contribui para o processo de competitividade. Para isso, ela realiza a aproximação entre a filosofia, metas e objetivos da empresa e os trabalhadores, investindo na transformação destes em agentes de competição. Dessa forma, o discurso empresarial presente nessa literatura afirma que é papel do RH tanto transmitir quanto transformar os trabalhadores em elementos chaves na concorrência. Ainda advogam que é necessário à área renovar suas ações, superando as antigas visões mecanicistas de administração de pessoal (Chiavenato, 1998, 2008).

Outro elemento marcante desse discurso é a defesa da existência de uma nova visão de homem em todo o processo. É possível elencar alguns aspectos que a delimitam: a) consideração dos trabalhadores como pessoas, e não somente insumos ou equipamentos da empresa; b) são os trabalhadores que movimentam a estrutura da empresa, impulsionando-a e atualizando-a de acordo com as pressões internas e externas; c) são parceiros da empresa, havendo um movimento recíproco de investimento e retorno de resultados; d) são bases para criação, manutenção e desenvolvimento das competências presentes na empresa; e) são o principal ativo da empresa por agregarem inteligência a essa estrutura (Bohlander et al., 2003; Chiavenato, 2008). Nessa linha, propõe-se mudar a denominação da área, considerando uma possível mudança de visão de homem e de preceitos teóricos, passando a se chamar área de Gestão de Pessoas (Chiavenato, 2008).

Assim, a área de Gestão de Pessoas expressa essa renovação - de ideias e de posição na empresa - através de suas políticas internas. Um dos elementos principais presentes no discurso propalado sobre gestão de pessoas é a importância da definição das políticas, visto que elas dão o tom estratégico-competitivo ao modo de administrar o pessoal. 


\section{As políticas de gestão de recursos humanos}

Segundo o discurso ideológico presente na literatura listada na sessão anterior, as políticas de RH seriam guias para como e quando proceder, sempre direcionadas aos objetivos organizacionais.

Assim sendo, existiriam seis processos principais sobre os quais as políticas de gestão de RH deveriam ocupar-se: agregação, aplicação, recompensa, desenvolvimento, manutenção e monitoramento dos recursos humanos da empresa. Logo, as políticas devem definir onde realizar o recrutamento de pessoal, a partir de que critérios realizar a seleção, como movimentar os cargos, remunerar, motivar, dentre outros (Chiavenato, 1998, 2008).

Alguns autores, como Carvalho e Nascimento (1993), Chiavenato (1998) e Dutra (2006), pressupõem que a construção das políticas de RH é um processo integrativo que objetiva unificar as visões tanto da cúpula gestora como dos trabalhadores alocados nos diversos níveis hierárquicos, intentando que as políticas traduzam práticas conciliadas entre eles.

Além disso, as políticas de RH assumem, segundo o discurso empresarial, um caráter contextual, referindo-se a cada realidade histórica e social vivenciada pelas empresas. Com isso, elas se revelam contingenciais, considerando que devem estar indiscutivelmente integradas à estratégia empresarial, alinhando-se para o atendimento das metas e objetivos de cada empresa. Por outro lado, é característica desse mesmo discurso a existência de algumas prescrições normativas que servem de matriz para o pensamento em cada instituição.

Considerando esse caráter, emerge no momento atual uma forte discussão relacionada às competências dos trabalhadores. Historicamente, essa discussão ganhou vigor na década de 1990, quando do modelo de gestão estratégica de pessoas, advogando pelas competências como a mola mestra para o desenvolvimento das empresas (Fischer, 2002). Retomando o discurso reafirmado por trabalhos recentes (Chiavenato, 2008; Dutra, 2006; Fischer, 2002; M. T. L. Fleury \& A. Fleury, 2001; M. T. L. Fleury, 2002; Prahalad, 1999; Zarifian, 1990), é posta como imperativa para as empresas a consideração das competências das pessoas como insumo do seu processo de funcionamento. Em termos gerais, as competências podem ser definidas como:

Um saber agir responsável e reconhecido, que implica mobilizar, integrar e transferir conhecimentos, recursos e habilidades, que agreguem valor econômico à organização e valor social ao indivíduo (M. T. L. Fleury \& A. Fleury, 2001, p. 188).

Diante disso, alguns autores, como Chiavenato (2008), Dutra (2006), Robbins (2005) e Ulrich (2003), oferecem indícios de algumas tendências gerais nas políticas de RH como propostas de maior participação e autonomia dos funcionários na administração do trabalho, foco no desenvolvimento do pessoal e a flexibilização dos contratos de trabalho.

Com relação ao primeiro ponto, observam-se as propostas de muitas empresas para que os trabalhadores tenham liberdade de utilizar sua criatividade, trazendo inovação para os processos das empresas (Bohlander et al., 2003). Além disso, os trabalhadores são incentivados, através de diversas políticas, a estabelecer um sentimento de pertencimento à empresa, tomando para si as responsabilidades de prover mudanças significativas no contexto de trabalho. Assim, eles são convocados a integrar a empresa, implicando-se subjetivamente nesse espaço e depositando nele contribuições únicas e individuais através de sua criatividade e competências pessoais (Ulrich, 2003). Por meio desse processo, busca-se sintonizar a empresa tanto com as demandas externas (as mudanças são realizadas por setores, ora independentemente, ora atrelados ao todo organizacional) quanto com as internas (provenientes dos trabalhadores, que expressam as necessidades de suprimentos para execução 
de suas atividades). Um exemplo expressivo desses pressupostos são os Círculos de Controle de Qualidade - advindos do modelo toyotista -, que são reuniões periódicas entre os participantes de um setor para deliberar quanto aos problemas enfrentados e gerar soluções criativas em resposta a estes, tendo por finalidade incrementar a produtividade do setor e da empresa (Freyssenet \& Hirata, 1985).

Outro reflexo são as propostas de equipes de trabalho e de horizontalização das hierarquias, as quais têm por pano de fundo a busca pela diminuição dos hiatos dentro dos setores, das relações assimétricas de poder, focalizando na troca de conhecimentos e experiências entre os pares, para viabilizar a construção de propostas inovadoras (Pimenta, 1999). Incluem-se ainda os projetos de redesenho de cargos, que visam agregar a uma mesma função diversas atividades, bem como o rodízio de tarefas, ambos sob a justificativa de enriquecimento desse cargo (Bohlander et al., 2003).

Uma segunda perspectiva pela qual a autonomia dos trabalhadores pode ser analisada é no trato da gestão de carreiras (Chiavenato, 2008; Dutra, 2006; Robbins, 2005; Ulrich, 2003). Os autores da perspectiva empresarial apontam que no atual contexto do mercado de trabalho os sujeitos teriam a possibilidade de avaliar sua inserção na empresa, na medida em que esta apresenta uma filosofia alinhada com seus valores pessoais. Seria estabelecida uma relação de escolha entre ambas as partes: os trabalhadores, por um lado, escolheriam as empresas que apresentassem filosofia semelhante às deles, e as empresas, por outro lado, selecionariam os sujeitos que possuíssem as características - ou competências - que melhor seriam aproveitadas dentro da instituição.

Além disso, dentro dessa lógica, seria incumbência do trabalhador buscar desenvolvimento profissional, através de cursos, treinamentos e capacitações, e da empresa estimular tal processo, por meio de políticas de recursos humanos que incentivassem essa ação. Os já referidos autores acrescentam que esse processo de desenvolvimento profissional/pessoal deve ser contínuo e o trabalhador não deve se limitar às estruturas organizacionais para efetiválo.

Já a terceira tendência, a de flexibilização dos contratos de trabalho, apresenta-se como mais uma prescrição indicada pelo discurso ideológico empresarial. $\mathrm{O}$ pressuposto básico da flexibilização é a negociação no um a um, pela qual a empresa e o trabalhador negociam condições sobre as quais um trabalho específico ocorrerá. Assim, elementos como volume de trabalho, horários, contrato, remuneração, entre outros, são postos na negociação a fim de alcançar maior lucratividade empresarial (Dutra, 2006). Traduzindo essas propostas para as políticas de $\mathrm{RH}$, emergem propostas de flexibilização do horário e do regime de trabalho como os home offices, o "horário núcleo" e os bancos de horas, bem como os contratos por projetos (Paradela \& Peeters, 2001).

Acrescentam-se a essas políticas aquelas voltadas para a remuneração nas quais os salários, benefícios e ganhos monetários adicionais são postos em função de um marco de produtividade. Percebe-se esse processo nas políticas de meta de produção e de benefícios negociáveis que imprimem como marca a existência, dentro de um mesmo setor, de funcionários com os mesmos cargos, mas com remunerações variadas (Dutra, 2006).

Além dessas tendências gerais apontadas, é possível verificar outras que se apresentam como emergentes nesse quadro. Nesse rol, incluem-se as políticas de qualidade de vida no trabalho (QVT), que, apesar de já serem tratadas no campo teórico e operacionalizarem-se em algumas empresas de grande porte, ainda estão em processo de institucionalização e de expansão.

De maneira geral, a literatura mais difundida no meio gerencial trata com parcialidade essa temática. As discussões sobre QVT, a despeito de ter raízes em diversas lutas dos trabalhadores por melhores condições de trabalho e possibilidades de bem-estar em seu 
labor (Lacaz, 2000), são escamoteadas para a dimensão individual do fenômeno. Assim como afirma Rodrigues (1992, citado por Albuquerque \& França, 1998), um dos motes das ações de QVT é o gerenciamento de estresse. Seguindo nessa discussão, Kompier e Kristensen (2003), analisando a literatura internacional - que em muito influencia as obras que circulam no Brasil - sobre intervenções organizacionais em estresse, identificaram que eram propaladas comumente as ações remediadoras e focalizadas nos trabalhadores sem, concomitantemente, pensar mudanças no ambiente organizacional.

Tendo essa primeira caracterização, baseada na literatura corrente nos meios empresariais, nota-se que as novas ações e mecanismos de gestão buscam atender as reações dos trabalhadores aos antigos modelos de gerenciamento empresarial. Em uma nova sociedade na qual a liberdade, a criatividade e a autonomia são valorizadas, eram emergentes mudanças nos modos de se operacionalizarem os processos das empresas. Com isso, torna-se necessário analisar mais cuidadosamente as implicações e consequências dessas políticas de RH para os trabalhadores.

\section{Críticas aos modelos de gestão inspirados no toyotismo e às políticas de gestão de recursos humanos}

Em contraponto ao discurso empresarial sobre o processo de gestão de RH desponta outra literatura, derivada principalmente da Sociologia e da Psicologia do Trabalho, como os trabalhos de Alves (2011), Antunes (2007, 2010), Bernardo (2009), Brito (2005), Figueiredo (1989), Gounet (1999), Jacques (1989), Lacaz (2000), Merlo (2007), Ramalho (2000), Sato $(1997,2009)$ e Siqueira (2009), que se propõem a lançar um olhar crítico sobre as afirmativas desse discurso.

De acordo com essa literatura crítica, os novos modelos de gestão possuem o intuito de intensificar a exploração do trabalho (Antunes, 2007, 2010) e alicerçam suas ações na cooptação subjetiva dos trabalhadores (Alves, 2011). Diferentemente do propalado, considerase que os modelos de gestão baseados no toyotismo não são propostas radicalmente novas no campo da relação capital-trabalho: eles seriam o avanço da exploração do trabalho, que já era central nos modelos tayloristas/fordistas. O que o toyotismo apresenta como inédito é a assunção da subjetividade do trabalhador como ponto nodal para a intensificação dessa exploração (Alves, 2011; Bernardo, 2009). Percebe-se, então, que muitas das ideias presentes nos textos empresariais a respeito da gestão de $\mathrm{RH}$ possuem como pano de fundo as propostas advindas do sistema toyotista de organização.

O processo de cooptação subjetiva pode ser definido como a agregação da cognição e afeto do trabalhador na execução do seu trabalho. Isto é, enquanto no taylorismo/fordismo a proposta era cindir a dimensão da ação da reflexão, no toyotismo a tentativa é integrar essas dimensões, considerando tanto ser essa divisão irreal como o aproveitamento da subjetividade do trabalhador ser altamente lucrativo (Alves, 2011). Alguns autores, como Antunes (2007), Bernardo (2009), Brito (2005), Siqueira (2009) e Gournet (1999), consideram que as empresas aderentes a esse padrão de organização do trabalho investem expressivamente na área de $\mathrm{RH}$ a fim de alcançar a cooptação subjetiva do trabalhador.

As análises dos efeitos desse processo levantam críticas ao discurso empresarial. Certos elementos básicos postos em pauta são: a falácia da autonomia dos trabalhadores, a construção de subjetividades inautênticas, o enfraquecimento das lutas políticas da classe trabalhadora e os efeitos negativos sobre a saúde do trabalhador. 
Pesquisando sobre esse processo no interior de duas indústrias automobilísticas brasileiras baseadas no toyotismo, Bernardo (2009) aponta que a autonomia e a participação do trabalhador dentro das empresas são pervertidas. A relação que se estabelece de abertura da empresa para a participação dos trabalhadores é limitada, dada a concepção que se divulga: o trabalhador deve refletir sobre seu processo de trabalho a fim de encontrar soluções criativas e gerar inovações nos procedimentos, na direção de ampliar a produtividade. Contudo, essa autonomia é podada no instante em que se adentra em propostas por melhores condições de trabalho.

Na mesma direção, Ramalho (2000), comentando Appay (1993, 1997), expõe que a autonomia dos sujeitos dentro das organizações é perpassada imediatamente pelo controle das gerências, que, por sua vez, remetem diretamente ao discurso da "demanda do cliente". O que se alardeia na literatura empresarial como um avanço na humanização do trabalho, pelo caminho da democratização das relações dentro da empresa, com a maior participação do trabalhador, operacionaliza-se muito mais como um direcionamento de suas possibilidades de ações do que de uma real participação (Alves, 2011).

Um segundo ponto que se relaciona estreitamente com essa discussão é como se interfere na subjetividade dos trabalhadores. Segundo uma análise de Siqueira (2009) do discurso empresarial, as empresas possuem mecanismos de sedução do trabalhador para que ele compartilhe com esta os mesmos valores e objetivos e, com isso, oriente suas ações com as almejadas pela empresa. Assim, são comuns promessas de sucesso futuro acompanhadas pela exigência de a empresa ocupar lugar central na vida do trabalhador, estando as demais dimensões de sua vida em função dela: a família, o lazer, os estudos e qualquer outra atividade devem servir ao desenvolvimento profissional do sujeito, e, muito mais, ser convertido em aprimoramentos para a empresa.

Desse modo, assim como ocorre com a autonomia cerceada, o próprio desenvolvimento subjetivo através do trabalho é condicionado à produtividade empresarial, o que limita, em grande parte, as potencialidades de o sujeito emergir em suas singularidades. Do mesmo modo que expõe Antunes (2007) - comentando as reflexões de Lukács (1980) e Tertulian (1993) -, esses mecanismos de gestão privam o trabalhador de desenvolver suas potencialidades, na medida em que há o condicionante do capital nessa equação. $\mathrm{O}$ autor complementa que no modelo toyotista, além de haver um estranhamento do produto produzido pelo trabalhador (fato que ocorria dentro do taylorismo/fordismo), há o estranhamento de sua própria subjetividade, já que esta toma como referência os pressupostos empresariais (orientados para o atendimento das demandas da clientela), desenvolvendo-se alheia ao próprio sujeito.

Em contrapartida, a construção de uma subjetividade autêntica é iminente à implosão da submissão dos sujeitos à heterodeterminação do status quo social capitalista. Em outros termos, apenas há subjetividade autêntica quando presente a autodeterminação do sujeito que extrapola a sujeição de suas possibilidades de ser aos preceitos capitalistas. A mais, no atual contexto, como já apontado em sessões anteriores, adensam-se fortemente as práticas alienantes que impedem os trabalhadores de encontrar essa autodeterminação, na medida em que todos os espaços de "tempo livre" são cerceados pela submissão ao capital.

Diversas políticas de gestão de RH corroboram para esse controle subjetivo, sendo uma delas a de desenvolvimento de pessoal. Brito (2005), em um estudo a respeito dessas políticas e práticas, esclarece que estas, em todas as suas dimensões, são unilateralmente desenvolvidas. A autora defende que os motivos que fundamentam os programas de desenvolvimento de pessoal, bem como seus objetivos e conteúdos, são formulados de acordo com as necessidades das empresas de aprimorar sua produtividade, e não de tratar questões de maior relevância para a classe trabalhadora. Porém, os trabalhadores não se mostram desavisados quanto às reais intenções que fundamentam esse processo. Para tanto, as empresas 
valem-se de argumentos que vão muito além de promessas falaciosas: é através da utilização de um discurso sobre o desemprego ${ }^{4}$ que a pressão pelo compartilhamento se opera.

Outra questão que corre em paralelo é com relação aos efeitos das políticas de gestão de RH no projeto de desmantelamento da força da luta da classe trabalhadora. Como apontado, é característico dessas políticas o incentivo ao trabalho em equipe: são difundidos os valores da cooperação, trabalho e integração no grupo para a realização das tarefas. Contudo, como bem discorrem Antunes (2007), Bernardo (2009) e Siqueira (2009), esses valores apresentam-se inevitavelmente em contradição ao da competitividade, o qual está igualmente em voga no discurso empresarial. Dessa forma, nas empresas que adotam os modelos inspirados no toyotismo, é comum encontrar o incentivo à cooperação entre os pares e a competitividade individual. Como exemplo, encontram-se tanto políticas voltadas para o incentivo ao trabalho em equipe (metas e remuneração por setor, estruturação do trabalho em equipes e os Círculos de Controle de Qualidade) como para o âmbito individual (metas e avaliações individuais).

Dessa situação emerge a conversão da cooperação do trabalho em equipe como meio para alcançar a competitividade individual. Dentro da equipe, compreende-se que a produção deva partir desta, mas, contraditoriamente, a atenção volta-se para o desempenho daqueles que se destacam. Nessas condições, ao invés de propalar a cooperação real e a solidariedade entre os trabalhadores, o que se tem é a efetivação da dissolução dos laços entre esses sujeitos, desconstruindo as possibilidades de mobilização coletiva (Antunes, 2007; Bernardo, 2009; Siqueira, 2009).

A problemática se expande da rivalidade entre os pares dentro das empresas para o cenário mais amplo das lutas e conquistas trabalhistas. Através da intensificação do discurso da competitividade e da responsabilização do trabalhador por sua "empregabilidade" (Caruso \& Pero, 1997), o sujeito ingressa em um processo de perda da percepção de que as suas lutas individuais manifestam-se como problema conjuntural de uma classe trabalhadora. Dessa ciranda, o resultado é o enfraquecimento da força de combate da classe trabalhadora pela particularização e individualização das questões trabalhistas no ínterim da consciência dos trabalhadores.

Nota-se, então, que as políticas atuais operacionalizam um pensamento que ataca o trabalho, enviesando a negociação entre este e o capital, já que o primeiro termo dessa dialética apresenta-se enfraquecido, dada a consciência reificada que se constrói nas relações atuais de trabalho (Antunes, 2007, 2010). Desse modo, as políticas de RH possuem papel fundamental na luta dos trabalhadores: por meio das negociações um a um, nas políticas nesse embate por ser em seu interior que o capital instrumentaliza e opera os mecanismos de particularização/individualização de remuneração, de avaliação, de concessão de benefícios, dentre tantas outras apontadas anteriormente, é que se desconstrói a visão de classe.

Nesse contexto da gestão baseada no toyotismo a saúde do trabalhador também é afetada. A respeito desse tema, Merlo e Lapis (2007) demonstram que essa estruturação da organização do trabalho faz emergirem questões diferenciadas dos outros modelos, o que acarreta novas relações entre o trabalho e a saúde. Para os autores, na égide dos modelos inspirados no toyotismo, são elementos chave para a compreensão da relação saúde e trabalho a intensificação do ritmo de trabalho (proporcionado pela utilização da tecnologia), o desgaste pela quantidade de horas trabalhadas e o envolvimento subjetivo com o trabalho (Merlo \& Lapis, 2007). Comentando sobre esse regime de intensificação da produção por trabalhador, seja pelo ritmo da máquina, seja pelas horas de trabalho a mais, Bernardino e Bento (2002) afirmam que no presente contexto encontra-se tanto a opressão física quanto a psicológica,

$4 \mathrm{Tal}$ discurso fora construído ao longo de quatro décadas, nas quais se adensou o desemprego estrutural no país (Pochmann, 2006b). Esse discurso, sedimentado, ainda hoje é utilizado no processo de negociação entre capital e trabalho (Boltanski \& Chiapello, 2009). A mais, é importante lembrar que, a despeito da redução geral nos níveis de desemprego, quando se estratifica tal análise pode-se constatar a falta de postos para absorver trabalhadores, como os mais novos e moradores de cidades de médio porte (Massad, 2010). 
haja vista que se conjugam os elementos já citados com as propostas de envolvimento subjetivo forçado dos trabalhadores.

\section{Notas sobre as políticas de gestão de recursos humanos e o psicólogo nas organizações}

Algumas reflexões são relevantes, baseadas no levantamento realizado até aqui. Primeiramente, é importante apreender que as políticas de RH são operacionalizadoras dos pressupostos toyotistas. É também por meio delas que a ideologia imanente à reestruturação do capital traduz-se no ambiente empresarial, sendo um ponto de mediação entre o trabalho e o capital. É possível afirmar isso quando se percebe que ela, por um lado, capta e expõe em linhas gerais quais são as intenções e motivações da cúpula e, por outro, estrutura as práticas direcionadas à gestão das pessoas de acordo com esses pressupostos.

Ao mesmo tempo em que as práticas e discursos empresariais baseados no toyotismo inauguraram diversos mecanismos que adensaram a exploração do capital sobre o trabalho, esses elementos abrem novos espaços para o avanço da luta trabalhadora. Um desses lócus é, certamente, o das políticas de RH nas empresas. Esse espaço deve despertar os interesses não somente dos preocupados com a produtividade empresarial: ele também pode vir a ser um importante caminho para que diversos ganhos da classe trabalhadora se concretizem.

É necessário ter no horizonte como atualmente a luta dos trabalhadores se operacionaliza. Bernardo (2009) e Sato $(1997,2009)$ sinalizaram que o processo de intensificação da exploração não é vivido de modo pacífico pelos trabalhadores, pelo contrário: são constatados, nos seus cotidianos, diversos processos de negociação e resistência. Assim como ocorreu no início da sociedade capitalista, ainda nos dias atuais é forte a contradição capital e trabalho e, muito mais, os processos de lutas e resistências empreendidos pelos trabalhadores.

Essas prerrogativas geram implicações para diversos atores envolvidos com esses processos. Todavia, dentro do escopo deste estudo, em caráter de reflexão, está em foco o papel dos sindicatos e dos psicólogos.

Como bem sinalizaram Antunes (2007) e Ramalho (2000), é necessário os sindicatos reverem a maneira com que são realizadas as intervenções junto às empresas a favor dos trabalhadores. Auxiliando na proposição de novos caminhos, Sato (2009) descreve um dos mecanismos utilizados pelos trabalhadores quando necessitam realizar alguma negociação particular: o uso dos conceitos oriundos do próprio discurso empresarial em seu favor.

Ampliando a utilidade desse instrumento, ele é um elemento válido para o diálogo entre empresas e sindicatos, havendo a reformulação dos discursos do primeiro, sem, necessariamente, perder o seu conteúdo reivindicatório. Em favor da "autonomia do trabalhador" ou da "qualidade", diversas novas propostas que beneficiam diretamente o trabalhador podem ser requeridas, muitas das quais na dimensão das políticas de RH.

Destacam-se, e encontram campo fértil nas empresas inspiradas no toyotismo, as políticas voltadas à qualidade de vida no trabalho e saúde mental do trabalhador. Nesse foco, os sindicatos devem atentar para que tais ações sejam orientadas para o contexto da empresa e do trabalhador de maneira ampla, fugindo de preceitos eminentemente subjetivistas e particularistas. Como destaca Lacaz (2000), é relevante que esses projetos tomem como norte a questão das condições de trabalho e fundamentalmente do controle que os trabalhadores possuem sobre esse. 
Um ponto que se instaura para a luta dos sindicatos junto às empresas é a implementação de políticas de RH que priorizem, de maneira radical, a humanização do trabalho, o que deve ser desenvolvido de acordo com os contextos particulares de cada empresa no país.

Nesse instante, o papel do psicólogo no processo de desenvolvimento dessas políticas apresenta-se de maneira mais clara. Ao passo que esse profissional, gradativamente, está ocupando os espaços de gerência dos setores de RH (Associação Brasileira de Recursos Humanos-SP, 2008), ele ganha papel de destaque na construção e operacionalização dessas políticas. Considerando essa nova condição, é fundamental que os psicólogos passem a ter no horizonte não somente a lucratividade empresarial, mas integrem, também, as necessidades e anseios da classe trabalhadora.

A atuação em atividades de qualidade de vida no trabalho e saúde mental do trabalhador, seguindo o norte já apontado, pode oferecer respostas ao que criticavam Figueiredo (1989) e Mello (1989) quando falavam do psicólogo inserido nas empresas como um profissional posto exclusivamente a favor da produtividade empresarial. Porém, são eminentes as limitações que o trabalho do psicólogo possui, dadas pela própria dinâmica social e por como ocorre a inserção desse profissional nas empresas.

Não é possível que ele se desatrele completamente das demandas empresariais, em favor das necessidades dos trabalhadores, tendo em vista que se inclui nesta última classe. Contudo, alguns caminhos alternativos são possíveis, como os apontados. As próprias ações de treinamento e desenvolvimento, como sinalizou Jacques (1989), podem ser uma via pela qual o psicólogo trabalhe questões como a consciência de classe e os direitos trabalhistas, dentro de algumas proporções.

Muito antes, é crucial, para qualquer ação voltada à melhoria das condições de vida e de trabalho da classe trabalhadora, a reorientação teórico-política desses profissionais. É necessário que os psicólogos, nesse contexto, tenham também conhecimentos que extrapolem os modismos e literaturas do discurso ideológico empresarial e aproximem-se das discussões da própria classe trabalhadora.

Outro ponto para esse debate é a consideração da inserção da Psicologia em outros espaços relacionados ao contexto do trabalho, como sindicatos e núcleos de atenção à saúde do trabalho. Esse processo pode corroborar a expansão de ações e a produção de conhecimentos que contribuam com a classe trabalhadora. Atualmente, na própria Psicologia, já se conta com um arsenal de pesquisas, principalmente do campo da Psicologia Social e do Trabalho e da Ergonomia, que se propõem a adotar um referencial teórico-metodológico que tenha em vista a orientação política desse profissional, ao mesmo tempo em que intenta dar subsídios para ações inovadoras tanto em espaços tradicionais como em novos locais. No entanto, é necessário que os profissionais tenham contato com essa literatura.

Como indicativo final, emerge, com grande importância, o lugar da formação básica do psicólogo. Sendo no período de graduação o momento em que os futuros profissionais entram em contato com conhecimentos que serão base para sua ação (Botomé \& Kubo, 2002), é fundamental que discussões a respeito do papel político desse profissional e de temáticas voltadas à classe trabalhadora estejam integradas nesse processo formativo.

\section{Referências}

Alves, G. (2011). Trabalho e subjetividade: o espírito do toyotismo na era do capitalismo manipulatório. São Paulo: Boitempo. 
Alves, V. (1995). Os impactos causados pela implantação de um programa de controle de qualidade de total (TQC) nas políticas de recursos humanos de uma organização: o caso Iochpe-Maxion S. A. Dissertação de mestrado, Universidade Federal de Santa Catarina, Florianópolis.

Antunes, R. (2007). Os sentidos do trabalho: ensaio sobre a afirmação e a negação do trabalho. São Paulo: Boitempo.

Antunes, R. (2010). Adeus ao trabalho? Ensaios sobre as metamorfoses e a centralidade no mundo do trabalho. São Paulo: Boitempo.

Aquino, C. P. (1980). Administração de recursos humanos. São Paulo: Atlas.

Alburquerque, L. G. (2002). A gestão estratégica de pessoas. In M. T. L. Fleury (Org.), As pessoas na organização (pp. 35-50). São Paulo: Editora Gente.

Alburquerque, L. G. \& França, A. C. L. (1998). Estratégias de recursos humanos e gestão da qualidade de vida no trabalho: o stress e a expansão do conceito de qualidade total. Revista de Administração, 33 (2), 40-51.

Associação Brasileira de Recursos Humanos-SP. (2008). Perfil do RH: Diversidade de formação caracteriza a área de RH. Recuperado em 7 de setembro de 2010 de http://www.abrhsp.org.br/site/jornais_read.asp?id=30.

Bernadino, M. T. S. M. \& Bento, P. E. G. (2002). Reestruturação produtiva, condições de trabalho e saúde no Brasil. Cadernos de Terapia Ocupacional da UFSCar, 10 (1), 19-29.

Bernardo, M. H. (2009). Trabalho duro, discurso flexível: uma análise das contradições do toyotismo a partir da vivência de trabalhadores. São Paulo: Expressão Popular.

Bohlander, G., Snell, S. \& Sherman, A. (2003). Administração de Recursos Humanos. São Paulo: Thomson.

Boltanski, L. \& Chiapello, E. (2009). O novo espírito do capitalismo. São Paulo: Martins Fontes.

Botomé, S. P. \& Kubo, O. M. (2002). Responsabilidade social dos programas de pós-gradução e formação de cientistas e professores de nível superior. Interação (Curitiba), 6 (1), 81-110.

Bottomore, T., Harris, L., Kiernan, V. G. \& Miliband, R. (2001). Dicionário do pensamento marxista. Rio de Janeiro: Zahar.

Brito, L. M. P. (2005). Gestão de competências, gestão do conhecimento e organizações de aprendizagem: instrumentos de apropriação pelo capital do saber do trabalhador. Fortaleza: Imprensa Universitária.

Caruso, L. A. C. \& Pero, V. (1997). Empregabilidade e reconversão profissional: trabalhadores desligados da indústria. São Paulo em Perspectiva, 11 (1), 70-81.

Carvalho, A. V. \& Nascimento, L. P. (1993). Administração de recursos humanos. São Paulo: Pioneira.

Chiavenato, I. (1998). Recursos humanos. São Paulo: Atlas.

Chiavenato, I. (2008). Gestão de pessoas. Rio de Janeiro: Elsevier.

Dutra, J. S. (2006). Gestão de pessoas: modelo, processos, tendências e perspectivas. São Paulo: Atlas.

Ferreira, C. G. O. (1997). O fordismo, sua crise e algumas considerações sobre o caso brasileiro. Nova Economia, 7 (2), 165-201.

Figueiredo, M. A. C. (1989). O trabalho alienado Eु o psicólogo do trabalho: algumas questões sobre o papel do psicólogo no controle da produção capitalista. São Paulo: Edicon.

Fischer, A. L. (2002). Um resgate conceitual e histórico dos modelos de gestão de pessoas. In M. T. L. Fleury (Org.), As pessoas na organização (pp. 11-34). São Paulo: Editora Gente.

Fleury, M. T. L. \& Fleury, A. (2001). Construindo o conceito de competências. Revista de Administração Contemporânea, 5 (especial), 183-196.

Fleury, M. T. L. (2002). A gestão de competência e a estratégia organizacional. In M. T. L. Fleury (Org.), As pessoas na organização (pp. 51-62). São Paulo: Editora Gente.

Freyssenet, M. \& Hirata, H. S. (1985). Mudanças tecnológicas e participação dos trabalhadores: os círculos de controle de qualidade no Japão. Revista de Administração de Empresas, 25 (3), 5-21.

Gounet, T. (1999). Fordismo e toyotismo na civilização do automóvel. São Paulo: Boitempo.

Havey, D. (1989). A condição pós-moderna: uma pesquisa sobre as origens da mudança cultural. São Paulo: Loyola.

Kompier, M. A. J. \& Kristensen, T. S. (2003). As intervenções em estresse organizacional: considerações teóricas, metodológicas e práticas. Cadernos de Psicologia Social do Trabalho, 6, 37-58.

Jacques, M. G. C. (1989). Uma proposta de redimensionamento do papel do psicólogo do trabalho. Psico, 17 (1), 15 21. 
Lacaz, F. A. C. (2000). Qualidade de vida no trabalho e saúde/doença. Ciência $\mathcal{E}$ Saúde Coletiva, 5 (1), 151-61.

Lacombe, B. M. B. \& Tonelli, M. J. (2001). O discurso e a prática: o que nos dizem os especialistas e o que nos mostram as práticas das empresas sobre os modelos de gestão de recursos humanos. Revista de Administração Contemporânea, 5 (2), 157-174.

Marras, J. P. (2000). Administração de recursos humanos: do operacional ao estratégico. São Paulo: Futura.

Marx, K. (2010). O capital (Crítica da Economia Política). Livro 1 - O processo de produção do capital. Rio de Janeiro: Civilização Brasiliense.

Massad, A. (2010, 20 de dezembro). Entre jovens e em cidades médias, país está longe do pleno emprego, diz economista. Rede Brasil Atual.

Merlo, A. R. C. \& Lapis, N. L. (2007). A saúde e os processos de trabalho no capitalismo: reflexões na interface da psicodinâmica do trabalho e da sociologia do trabalho. Psicologia $\mathbb{E}$ Sociedade, 19 (1), 61-68.

Mészáros, I. (2004). O poder da ideologia. São Paulo: Boitempo.

Mészáros, I. (2006). Desemprego e precarização: um grande desafio para a esquerda. In R. Antunes (Org.), Riqueza e miséria do trabalho no Brasil (pp 27-44). São Paulo: Boitempo.

Mintzberg, H. (2004). Ascensão e queda do planejamento estratégico. Porto Alegre: Bookman.

Mohrman Jr, A. M. \& Lawler III, E. E. (1995). Administração de recursos humanos: construindo uma parceria estratégica. In J. R. Galbraith \& E. E. Lawler III (Orgs.), Organizando para competir no futuro. São Paulo: Makron Books.

Nakano, Y. (1994). Globalização, competitividade e novas regras de comércio mundial. Revista de Economia Política, $14(4), 7-30$.

Paradela, T. \& Peeters, S. (2001). “Trabalhar ou ficar em casa?”: perspectivas do trabalho remoto. Anais do Encontro Nacional de Engenharia de Produção, 21. Salvador: Associação Brasileira de Engenharia da Produção.

Pimenta, S. (1999). Recursos Humanos: uma dimensão estratégica. Belo Horizonte: UFMG.

Prahalad, C. K. (1999). Reexame de competências. Revista HSM Management, 17, 40-46.

Pochmann, M. (2006a). Desempregados do Brasil. In R. Antunes (Org.), Riqueza e miséria do trabalho no Brasil (pp. 23-40). São Paulo: Boitempo.

Pochmann, M. (2006b). Rumos da política do trabalho no Brasil. In M. O. S. Silva \& M. C. Iazbeck (Orgs.), Políticas públicas de trabalho e renda no Brasil contemporâneo (pp. 23-40). São Paulo: Cortez.

Ramalho, J. R. (2000). Trabalho e sindicato: posições em debate na Sociologia hoje. Dados, 43 (4), 761-777.

Robbins, S. P. (2005). Comportamento organizacional. São Paulo: Pearson Prentice Hall.

Sato, L. (1997). Astúcia e ambiguidade: as condições simbólicas para o replanejamento negociado do trabalho no chão de fábrica. Tese de doutorado, Instituto de Psicologia, Universidade de São Paulo, São Paulo.

Sato, L. (2009). Trabalho: sofrer? Construir-se? Resistir? Psicologia em Revista, 15 (3), 189-199.

Siqueira, M. V. S. (2009). Gestão de pessoas e discurso organizacional. Curitiba: Juruá.

Ulrich, D. (2003). Recursos humanos estratégicos: novas perspectivas para os profissionais de RH. São Paulo: Futura.

Zarifian, P. (1990). As novas abordagens da produtividade. In R. M. S. Soares (Org.), Gestão de empresas e competitividade (pp. 73-97). Brasília: IPEA/IPLAN.

\section{Endereço para correspondência}

fellipecoelholima@gmail.com,pcamilatorres@gmail.com

Recebido em: 16/09/2010

Revisado em: 26/01/2011

Aprovado em: 26/02/2011 